\title{
Association between Anxiety and Sleepiness in Medical Students of the University of Guadalajara (Mexico)
}

Asociación entre ansiedad y somnolencia diurna en estudiantes de medicina de la Universidad de Guadalajara (México)

Associação entre ansiedade e sonolência diurna em estudantes de medicina da Universidade de Guadalajara (México)

González-Heredia Omar Nahum ${ }^{1}$

Hernández-Corona Diana Mercedes²

González-Ramírez Leivy Patricia ${ }^{3}$

Vazquez Jáuregui Adriana Iveth ${ }^{4}$

Valle Reyes Araceli ${ }^{2}$

Aguilar Alarcón Mónica Daniela²

González-Heredia Tonatiuh²*

1 Unidad Médico Familiar 178 del Instituto Mexicano del Seguro Social, Zapopan, Jalisco (México).

2 Departamento de Ciencias Biomédicas, Centro de Investigación Multidisciplinario en Salud, Doctorado de Investigación Multidisciplinario en Salud, Centro Universitario de Tonalá, Universidad de Guadalajara, Jalisco (México).

3 Tecnologico de Monterrey, Escuela de Medicina y Ciencias de la Salud, Monterrey (México).

4 Universidad del Valle de México, Campus Zapopa (México).

Omar Nahum González-Heredia, oRCID: https://orcid.org/0000-0003-3705-4646. Diana Mercedes Hernández-Corona, orciD: https://orcid.org/0000-0002-8631-9201 Leivy Patricia González-Ramírez, ORCID: https://orcid.org/0000-0002-2952-2836 Adriana Iveth Vázquez Jáuregui, oRCID: https://orcid.org/0000-0001-8598-0615 Araceli Valle Reyes, oRciD: https://orcid.org/0000-0002-4110-0011 Mónica Daniela Aguilar Alarcón, oRciD: https://orcid.org/0000-0001-8118-4822 Tonatiuh González-Heredia, ORCID: https://orcid.org/0000-0003-4089-5462

*Autor de correspondencia: drtonatiuhgh@live.com.mx 
Received: 2021, January 18• Approved: 2021, November 29

Doi: https://doi.org/10.12804/revistas.urosario.edu.co/revsalud/a.10042

To cite this article: González-Heredia ON, Hernández-Corona DM, González-Raírez LP, Vazquez Jáuregui AI, Valle Reyes A, Aguilar Alarcón MD, González-Heredia T. Association between Anxiety and Sleepiness in Medical Students of the University of Guadalajara (Mexico). Rev Cienc Salud. 2022;20(1):1-12. https://doi.org/10.12804/revistas.urosario.edu.co/revsalud/a.10042

\section{Abstract}

Introduction: Medical students could potentially be considered as a vulnerable group in terms of increased risk for anxiety and sleep disorders. This could be caused by high academic demands, and high levels of stress. There is little information, however, when it comes to the relationship between anxiety and excessive daytime sleepiness among medical students, and the potentially negative effects this relationship could have upon student health and academic performance. The objective was to identify the association between anxiety and excessive daytime sleepiness in medical students of the University of Guadalajara (Mexico). Materials and methods: A cross-sectional study was carried out, evaluating 173 students between January and April of 2019. The Epworth Sleepiness Scale was used for the determination of excessive daytime sleepiness, while the anxiety symptoms were measured using the Beck Anxiety Inventory. According to the cut-off points for the Epworth scales, the cut-off point was from 10 and for the Beck anxiety inventory it was 8. Chi square and Fisher's exact test were used for statistical analysis. A value of $p<0.05$ was considered statistically significant. Results: Statistically significant differences were found between the students when comparing the presence and absence of excessive daytime sleepiness and anxiety with a value of $p=0.036$ and Odds Ratio of 2.161. Conclusion: A high prevalence of anxiety and insomnia was found in the group of medical students which was evaluated. Additionally, it was found that students who suffer from anxiety are more likely to develop excessive daytime sleepiness.

Keywords: Medical students; sleepiness; sleep disorders; anxiety; anxiety symptoms.

\section{Resumen}

Introducción: los estudiantes de medicina pueden ser considerados un grupo vulnerable para presentar ansiedad y trastornos del sueño, debido a las altas exigencias académicas y al estrés; sin embargo, se cuenta con pocos datos sobre la relación entre la ansiedad y la somnolencia en estudiantes de medicina, relación que podría generar complicaciones tanto académicas como de salud. El objetivo fue la asociación entre ansiedad y somnolencia excesiva diurna en estudiantes de medicina de la Universidad de Guadalajara (México). Materiales y métodos: estudio transversal con 173 estudiantes entre enero y abril del 2019. Para la determinación de somnolencia excesiva diurna se aplicó la Escala de Somnolencia de Epworth (punto de corte $=10$ ), mientras que para evaluar los síntomas de ansiedad excesiva se utilizó el Inventario de Ansiedad de Beck (punto de corte $=8$ ). Se emplearon chi cuadrado y la prueba exacta de Fisher para el análisis estadístico. Se consideró estadísticamente significativo un valor de $p<0.05$. Resultados: se encontraron diferencias estadísticamente significativas entre los estudiantes al comparar la presencia y la ausencia de somnolencia y ansiedad con un valor de $p=0.036$ y un odds ratio de 2.161. Conclusión: hay una alta prevalencia de ansiedad e insomnio en los estudiantes de medicina evaluados, y aquellos con ansiedad tienen mayor probabilidad de desarrollar somnolencia excesiva diurna.

Palabras clave: estudiantes de medicina; somnolencia; trastornos del sueño; ansiedad; síntomas de ansiedad.

\section{Resumo}

Introdução: estudantes de medicina podem ser potencialmente considerados um grupo vulnerável em termos de risco aumentado para ansiedade e distúrbios do sono. Isso pode ser causado por altas demandas acadêmicas e altos níveis de estresse. No entanto, há poucas informações sobre a relação entre ansiedade e sonolência diurna excessiva entre estudantes de medicina e os efeitos potencialmente negativos que 
essa relação pode ter sobre a saúde e o desempenho acadêmico dos alunos. O objetivo foi identificar a associação entre ansiedade e sonolência diurna excessiva em estudantes de medicina da Universidade de Guadalajara (Mêxico). Materiais e métodos: estudo transversal, avaliando 173 alunos entre janeiro e abril de 2019. A Escala de Sonolência de Epworth (ponto de corte $=10$ ) foi utilizada para a determinação da sonolência diurna excessiva, enquanto os sintomas de ansiedade foram medidos por meio do Inventário de Ansiedad de Beck (ponto de corte $=8$ ). Qui-quadrado e prova exata Fisher foram usados para análise estatística. Um valor de $p<0,05$ foi considerado estadísticamente significativo. Resultados: foram encontradas diferenças estatisticamente significantes entre os alunos ao comparar a presença e ausência de sonolência diurna excessiva e ansiedade com um valor de $p=0,036$ e um Odds Ratio de 2,16. Conclusão: foi encontrada alta prevalência de ansiedade e insônia no grupo de estudantes de medicina avaliados. Além disso, verificou-se que os alunos que sofrem de ansiedade têm maior probabilidade de desenvolver sonolência diurna excessiva.

Palavras-chave: estudantes de medicina; sonolência; distúrbios do sono; ansiedade; sintomas de ansiedade.

\section{Introduction}

$A$ nxiety, defined as a general state of agitation, worry or restlessness, generally manifests ious anticipation, increased levels of stress and tension in the face of potentially distressing situations, and the avoidance of stimuli or situations which could trigger anxiety (1). This could lead to additional operational limitations in every-day life. Anxiety can represent an adaptive state since it is characterized by the presence of subjective feelings of tension and apprehension; this can be a relatively stable state throughout life, or it could manifested as an anxiety disorder, which is considered as an individual's tendency to perceive a greater number of situations as potentially dangerous, thus overvaluing the risks and minimizing the resources they possess to deal with them. In Mexico, the prevalence of anxiety according to the results of the National Survey of Psychiatric Epidemiology in 2002, is estimated at $18.5 \%$ in women and $9.5 \%$ in men (1-3). Reports indicate that approximately 1 in 4 medical students suffer from anxiety over the course of their university degree which persists well into their clinical practice and internship years (4).

There is evidence to suggest that psychiatric disorders and sleep are significantly related, given their complex bidirectional relationship (5). Anxiety can manifest as certain complications which could interfere with an individual's normal activity; this is where sleep disorders come into play. This relationship between anxiety and excessive daytime sleepiness (EDS), defined by the ICsD-3 as daily episodes of an irrepressible need to sleep or daytime lapses into sleep, could lead to alterations in an individual's capacity to concentrate, and have an impact on reasoning which could manifest as irritability and depression or other health complications (6). This condition affects the professional, social or family life, and causes con- 
centration and memory problems. Unfortunately, despite the high prevalence, sleep disorders remain poorly identified; less than $20 \%$ of individuals with insomnia are correctly diagnosed and treated (7).

Attempts have been made to determine which variables could potentially increase the risk of developing EDs. Obesity, gender, energy expenditure, inadequate sleep duration and obstructive sleep apnea have been some of the variables associated with this condition. Less consistent evidence has also been described for certain diseases such as metabolic syndrome, diabetes, hypertension, hyperlipidemia, their respective treatments, alcohol consumption, diet, physical activity and smoking (8-10).

Certain groups such as women, night watchmen and undergraduate medical students have been shown to have a higher prevalence for EDs, therefore a special emphasis must be placed on early prevention and opportune treatment for these individuals (11). University students are subjected to a multitude of factors such as high academic demands, inadequate management of failure or rejection, constant changes in study pace, increased subject load and school activities, as well as alterations in sleep patterns and inappropriate dietary choices, which makes them one of the more vulnerable groups for the development of anxiety and associated sleep disorders. Studies indicate that students within the field of healthcare are generally exposed to additional factors and stressful situations such as death, illness, the mishandling of emotions and other associated situations which could further increase their risk of developing anxiety or sleep disorders (12-14).

Sleep disorders are common among the university population, especially among medical students which generally have a higher risk for developing certain sleep disorders such as insomnia and EDS given their exposure to increased academic demands, inadequate handling of failure or rejection, constant changes of study pace, excessive course and school activity load, and altered sleep patterns. Insomnia and EDs have been shown to increase the risk of developing depression, anxiety and other psychiatric disorders. Insomnia and EDs, by themselves, are not symptoms of anxiety, however, anxiety disorders are frequently associated with sleep disorders (15).

Several studies carried out in pre-graduate and postgraduate medical students have demonstrated that the main sleep disorder among this population is the lack-there-of, which directly impacts academic performance and overall health. This sleep deficit among medical students specifically has a negative impact upon cognitive skills, the ability to concentrate and the comprehension of certain concepts or academic texts, which leads to poor academic performance (16-18).

Medical training requires long shifts and students must comply with strict academic standards and clinical practice hours, which decreases the time available for and the quality of sleep. Sleep deficiency is also common at a professional level given the long working 
hours associated with hospital rotations, however, this could lead to decreased professional performance which could affect the safety of both doctor and patient alike $(19,20)$.

Scientific literature indicates that medical students are exposed to greater levels of stress than other undergraduate degrees, which could contribute to the development of anxiety and / or EDS. EDS and other sleep disorders contribute to the deterioration of cognitive abilities, motor and social skills, and could lead to certain behavioral disorders which could produce anxiety and depression, thus diminishing academic motivation and compromising a student's mental and physical health $(16,20)$.

However, despite this information, there is little data regarding the relationship between anxiety and sleepiness in medical students; a relationship that could lead to both academic and health complications among students. Therefore, the main objective of this study was to identify the association between anxiety and EDs among medical students in the University of Guadalajara.

\section{Materials and methods}

A analytical cross-sectional study was carried out between January and March of 2019. medicine of the University of Guadalajara, was used out of a population of 1,000 students, with a margin of error of $10 \%$ and a confidence level of $99 \%$.

According to the inclusion criteria; both men and women, who were actively enrolled in the medical program, from 18 to 30 years of age, were selected. Regarding the exclusion criteria; consumers of hallucinogens, heavy users of caffeine or energizing beverages, individuals previously diagnosed with anxiety and insomnia, or who had any other psychiatric disorder requiring medical treatment at the time of the study, were excluded.

The Beck Anxiety Inventory (BAI) was used to evaluate the severity of any anxiety related symptoms and to differentiate them from depression. This tool could be used in clinical or experimental studies, both in a psychiatric and normal population. The questionnaire consists of 21 questions, providing a score ranging between 0 and 63. Each item is scored from 0 to 3, with 0 corresponding to "not at all," 1 to "mildly, but it didn't bother me much," 2 to "moderately - it wasn't pleasant at times," and 3 to "severely, it bothered me a lot." The symptoms refer to any experience over the last week to the current moment. The total score is the sum of all the items. A total score between 0 and 7 is interpreted as a minimum level of anxiety, from 8 to 15 as mild, from 16 to 25 as moderate, and from 26 to 63 as severe (21).

The reliability index for the complete scale was $\alpha=0.83$. Testing norms for the Mexican population were determined based on the percentile range. The test-retest reliability of the inventory was obtained ( 20 days between each application); the intra-class correlation index 
was $r=0.75$. The convergent validity was obtained by correlating the inventory scores with those of the State Trait Anxiety Inventory; with the state anxiety scale: $r=0.60$; with that of trait anxiety, $r=0.59$. Patients with anxiety disorders obtained significantly higher mean scores than subjects from a healthy population (21).

The Epworth Sleepiness Scale is a self-reporting instrument consisting of 8 items developed by Johns to assess EDS, based on the predisposition to fall asleep in eight situations. The participant must answer each item on a scale of 0-3, where 0 means no probability of falling asleep and 3 high probability. The sum of the scores in each item provides the total score, with a range of 0-24. A score lower than 10 is considered normal, while a score of 10-12 is indicative of marginal sleepiness and a score above 12 is suggestive of excessive sleepiness. The scale has an acceptable internal consistency, with coefficients of 0.73 in control subjects and 0.88 in patients with sleeping disorders, as well as high test-retest reliability (rho $=0.81)(22)$.

The Alcohol Use Disorders Identification Test (AudIT) tool was used to identify dependence or negative consequences due to alcohol consumption. AudiT is a tool that contains 10 questions that identify the use of alcohol over the last 12 months. Questions 4-6 identify symptoms related to alcohol dependence and questions 7-10 explore the negative consequences associated with alcohol consumption. Each question has three to five possible answers that can give a maximum score of 40 points. Based on the scores, an abstemious or low risk person can be identified by obtaining a score between 0 to 7 , while a score of 8 to 12 points indicates a person with risky use or alcohol abuse and a score of 13 to 40 indicates probable dependence (23).

AUDIT has been tested in the Mexican population with a sensitivity of $90 \%$ and specificity of $94 \%$. Different studies have validated it in adolescent populations and have reported it to be the instrument which best identifies the use and problems, or disorders associated with alcohol consumption in this type of population (24).

During the interview, the students were asked complementary questions with the intention of identifying sociodemographic characteristics, health status, and additional risk factors for sleep disturbances such as medications, alcohol consumption, and smoking. Regarding physical activity, 30 minutes of exercise a day for at least 5 days a week was considered adequate.

Descriptive statistics were used to characterize the sociodemographic and clinical variables of the participants. The Chi squared tests was used to determine if any differences existed with respect to the presence or absence of excessive daytime sleepiness (EDS), using to the Epworth Sleepiness Scale, in accordance with the sociodemographic and clinical characteristics and the presence of anxiety among medical students, the cut-off point to be considered with the presence of daytime sleepiness was 10 . The Odds Ratio was calculated with a $95 \%$ confidence interval for the variables with significance. 
The study was conducted in accordance with the principles of the Helsinki Declaration; the study corresponds to a risk-free investigation. The dignity of the subjects and the protection of their rights and their privacy were respected. All participants gave their written informed consent prior to participation in the study (25).

\section{Results}

$\mathrm{A}_{\text {criteria and the remaining } 7 \text { decided not to participate in the study. The total population }}^{\mathrm{n} \text { interview was conducted with } 195 \text { individuals, of which } 15 \text { did not meet the inclusion }}$ of students participating in the study was 173 students from the first to fifth year of medicine, with an average age of $20.9 \pm 2.2$ years, and a greater predominance of participation by women with 125 (72.3\%), compared to men with 48 (27.7\%).

Regarding occupation and marital status, 149 (86.1\%) of the students who participated in the study were full time students and $114(65.9 \%)$ were single. Alcohol consumption was present in 34 (19.7\%) students and only 76 (43.9\%) students were physically active as previously defined. 53 (30.6\%) of the students were overweight and 7 (4\%) were underweight.

Of the 173 students, $27.2 \%$ presented sleepiness according to the Epworth Sleepiness Scale, of which 15 students were classified as having excessive sleepiness. On the other hand, $59.5 \%$ of the students suffered from anxiety, with 33 students having moderate and 17 having severe anxiety according to BAI.

Metabolic diseases were present in 40 (23.1\%) students which included polycystic ovarian syndrome in 16 students, metabolic syndrome in 12 students, dyslipidemias in 5, hypertension in 1 , and hypothyroidism in 6.

Each of the sociodemographic (gender, age, marital status, occupation and education) and clinical factors (obesity, alcohol consumption, physical activity, preexisting metabolic disease, medication use) were analyzed, however no statistically significant differences were observed for these variables between groups with or without EDS.

Statistically significant differences were found between the students when comparing the presence and absence of sleepiness and anxiety (Table 1), with a $p=0.036$ and an Odds Ratio of 2.161 ( $\mathrm{cI}=1.042-4.479)$. A positive correlation was found between anxiety and sleepiness in medical students $(r=0.28$ and $p=0.000)$. 
Table 1. Comparison of the presence of anxiety among students with or without sleepiness ( $\mathrm{n}=173$ patients)

\begin{tabular}{lccc}
\hline & Global & With sleepiness & Without sleepiness \\
\cline { 2 - 4 } & $\mathbf{n}(\mathbf{\%})$ & $\mathbf{n ~ ( \% )}$ & $\mathbf{n}(\%)$ \\
\hline Anxiety & & & \\
\hline Present & $103(59.5)$ & $34(72.3)^{*}$ & $69(54.8)^{*}$ \\
\hline Absent & $70(40.5)$ & $13(27.7)^{*}$ & $57(45.2)^{*}$ \\
\hline
\end{tabular}

*A statistically significant difference with $p<0.05 ; n(\%)=$ Frequency (percentage).

\section{Discussion}

A $\mathrm{n}$ important and complex bidirectional relationship exists between psychiatric disorrisk for developing these disorders, in part due to certain stressors inherent to studying medicine, which subsequently interfere with student health and academic performance $(5,6,26,27)$.

According to a study carried out by Schlarb et al. and in agreement with the results found in our investigation, a significant association was demonstrated between psychiatric disorders and sleep disorders among students (10). This cross-sectional study applied an online survey to a total of 2831 students from Germany and Luxembourg. Sleep disorders were assessed using the Pittsburgh Sleep Quality Index and the Epworth Sleepiness Scale, as well as other tools to assess the presence of psychiatric disorders. The results indicated a high prevalence of sleep disorders among students from both countries, likewise, a significant relationship was found between sleep quality, EDs, depression scores, stress levels, and test anxiety between men and women. Nevertheless, no differences were observed between students of the different countries (13).

Despite the significant associations, one of the limitations of the aforementioned study is that students were not categorized based on the type of degree being studied. As mentioned previously, there are certain populations with a higher risk for developing these types of disorders, such as medical students, however no comparison was made between this group and students studying different degrees. The results also indicate that the prevalence of clinically significant anxiety among students was only $9.1 \%$ in contrast with our study with a prevalence of $28.9 \%$. This difference in terms of prevalence could be attributed to the different in inventories being used to measure anxiety, nevertheless, both inventories have been proven to be useful in determining the presence of anxiety (13). 
Choueiry et al. (25) conducted a cross-sectional study in 462 students studying medicine, odontology and pharmacy, where the association between insomnia and anxiety was evaluated by means of questionnaires such as: The Insomnia Severity Index, Pittsburgh Sleep Quality Index, Epworth Sleepiness Scale and the Generalized Anxiety Disorder Scale-7. Results indicated a clinically significant relationship between anxiety and EDs in 50.8\% compared to $30.9 \%$ with EDS alone in the absence of anxiety. These results agree with those found in our study which indicate a strong relationship between anxiety and EDs, based on the Epworth Sleepiness Scale, among medical students, regardless of gender, age, marital status, medication or the presence of other diseases (28).

A study carried out by De la Cruz-Vargas et al. focused on a population of medical students from the Ricardo Palma University, Lima, Peru (26). This study evaluated the association between anxiety and sleep disorders in 132 students; the Bar and the Oviedo Sleep Questionnaire for measuring the sleep/wake cycle of the patient were both used, and a statistically significant association was found between anxiety and insomnia, thus demonstrating the need to prioritize the timely detection and treatment of anxiety and insomnia. De la Cruz-Vargas et al. determined that the prevalence of insomnia was $31.8 \%$ which concurs with the results of our study in which it was $27.2 \%$. This similarity could be attributed to the similar characteristics of both study populations.

This corroborates the observation that medical students tend to have an increased risk for these types of disorders, once again highlighting the importance of timely prevention, diagnosis and treatment (26).

Within the limitations of this study, we could mention the difficulty of finding causalities using a cross-sectional design due to the bidirectional relationship which could exist between sleep disorders and anxiety, thus making it difficult to understand what the real cause could be, if anxiety causes sleepiness or vice versa. Another of the limitations is that our study included more women than men, which could be of note given the fact that the majority of scientific literature indicates that women have a greater risk of suffering from psychiatric and sleep disorders. Individual student characteristics, such as current semester, academic load, and increased or decreased course and clinical practice duties based on their current progression through the career (i.e., higher vs lower semesters) could have also played an important role in the results obtained. For this reason, these results must be interpreted with caution since they may not be applicable to other populations of women or men.

Our study revealed that medical students tend to develop certain sleep disorders associated with stress and anxiety within the first two years of university. This should be a major consideration when contemplating the possible repercussions that clinical practices and hospital rotations may have upon student's quality of sleep, and mental and physical health from the 4 th year onward. Although the results obtained cannot be generalized, they can be 
used to establish a precedent in support of certain changes in educational dynamics to provide a better emotional balance.

A high prevalence of anxiety related symptoms was found among the medical students evaluated, additionally, observations indicate that students with anxiety are more likely to develop excessive daytime sleepiness (EDS). Even with the availability of newer educational technologies, none are yet available which could better align and optimize the schedules between educational activities, hospital rotations and the intrinsic learning rhythms of medical students. These results support the need for the implementation of certain precautionary measures which could assist medical students with the prevention and management of anxiety and sleep disorders in the hopes of reducing academic and health related complications.

\section{Acknowledgments}

thank Assen Ognianov Iantchoulev for the editorial assistance in English.

\section{Authors' contribution}

\footnotetext{
11 the authors contributed to the stages of the analytical process, preparation of the man$\mathcal{1}$ uscript, and approval of the final text.
}

\section{Conflicts of interest}

None declared.

\section{References}

1. Castillo Pimienta C, Chacón de la Cruz T, Díaz-Véliz G. Ansiedad y fuentes de estrés académico en estudiantes de carreras de la salud. Inv Ed Med. 2016;5(20):230-7. https:// doi.org/10.1016/j.riem.2016.03.001

2. Medina-Mora ME, Borges G, Muñoz CL, Benjet C, Jaimes JB, Bautista CF, et al. Prevalencia de trastornos mentales y uso de servicios: resultados de la Encuesta Nacional de Epidemiología Psiquiátrica en México. Salud Ment. 2003;26(4):1-16.

3. Medina-Mora ME, Borges G, Lara C, Benjet C, Blanco J, Fleiz C, et al. Prevalence, service use, and demographic correlates of 12-month DSM-Iv psychiatric disorders in Mexico: 
results from the Mexican National Comorbidity Survey. Psychol Med. 2005;35(12):1773. https://doi.org/10.1017/S0033291705005672.

4. Reyes Carmona C, Monterrosas Rojas AM, Navarrete Martínez A, Acosta Martínez EP, Torruco García U. Ansiedad de los estudiantes de una facultad de medicina mexicana, antes de iniciar el internado. Inv Ed Med. 2017;6(21):42-6. https://doi.org/10.1016/j. riem.2016.05.004

5. Krystal AD. Psychiatric disorders and sleep. Neurol Clin. 2012;30(4):1389-1413. https:// doi.org/10.1016/j.ncl.2012.08.018

6. Sateia MJ. International classification of sleep disorders-third edition: highlights and modifications. Chest. 2014 Nov;146(5):1387-94. https://doi.org/10.1378/chest.14-0970

7. Ohayon MM. Epidemiological overview of sleep disorders in the general population. Sleep Med Res. 2011;(2):1-9.

8. Azad MC, Fraser K, Rumana N, Abdullah AF, Shahana N, Hanly PJ, Turin TC. Sleep disturbances among medical students: a global perspective. J Clin Sleep Med. 2015;11(1):69-74. https://doi.org/10.5664/jcsm.4370

9. Salazar Blandón DA, Castillo León T, Pastor Durango MDP, Tejada-Tayabas LM, Palos Lucio AG. Ansiedad, depresión y actividad física asociados a sobrepeso/obesidad en estudiantes de dos universidades mexicanas. Hacia Promoc Salud. 2016;21(2):99-113. https://doi.org/10.17151/hpsal.2016.21.2.8

10. Schlarb AA, Claßen M, Grünwald J, Vögele C. Sleep disturbances and mental strain in university students: results from an online survey in Luxembourg and Germany. Int J Ment Health Syst. 2017;11(1):24. https://doi.org/0.1186/s13033-017-0131-9

11. Ojeda-Paredesa P, Francis D, Estrella-Castilloa HARZ. Sleep quality, insomnia symptoms and academic performance on medicine students. Inv Ed Med. 2019;8(29):36-44. https:// doi.org/10.22201/facmed.20075057e.2019.29.1758

12. Hamui-Sutton L, Barragán-Pérez V, Fuentes-García R, Monsalvo-Obregón EC, FouillouxMorales C. Efectos de la privación de sueño en las habilidades cognitivas, psicomotoras y su relación con las características personales de los médicos residentes. Cir Cir. 2013;81(4):317-27.

13. AlDabal L, BaHammam, AS. Metabolic, endocrine, and immune consequences of sleep deprivation. Open Respir Med J. 2011;5:31. https://doi.org/10.2174/1874306401105010031

14. Amin HS, Almazroua IS, Alsahlan AS, Alrishan MA, Elmourad HM, Alotaibi MM, Almohaisin AI. Effect of sleep deprivation on the attitude and performance of medical students, Riyadh, Saudi Arabia. Int J Med Sci Public Health. 2016;5(3):575-580. https:// doi.org/10.5455/ijmsph.2016.17112015207

15. Quezada Canalle MA. Factores asociados a la presencia de somnolencia en estudiantes de medicina humana de una Universidad Peruana Privada año 2019. 2020. https://doi. org/10.17843/rpmesp.2019.364.4305

16. Goitein L, Shanafelt TD, Wipf JE, Slatore CG, Back AL. The effects of work-hour limitations on resident well-being, patient care, and education in an internal medicine residency program. Arch Intern Med. 2005;165(22):2601-6. https://doi.org/10.1001/ archinte.165.22.2601 
17. Fahrenkopf AM, Sectish TC, Barger LK, Sharek PJ, Lewin D, Chiang VW, et al. Rates of medication errors among depressed and burnt out residents: prospective cohort study. BMJ. 2008;336(7642):488-91. https://doi.org/10.1136/bmj.39469.763218.BE

18. Robles R, Varela R, Jurado S, Páez F. Versión mexicana del Inventario de Ansiedad de Beck: propiedades psicométricas. Rev Mex Psicol. 2001;18(2):211-18.

19. Sandoval-Rincón M, Alcalá-Lozano R, Herrera-Jiménez I, Jiménez-Genchi A. Validation of the Epworth sleepiness scale in Mexican population. Gac Med Mex. 2013;149(4):409-16.

20. Medina-Mora ME, Gómez-Mont F, Campillo-Serrano C. Validity and reliability of a high school drug use questionnaire among Mexican students. Bull Narc. 1981;33(4):67-76.

21. Mora-Ríos J, Natera G. Expectativas, consumo de alcohol y problemas asociados en estudiantes universitarios de la ciudad de México. Salud Publ Mex. 2001;43:89-96.

22. van Delden JJ, van der Graaf R. Revised cioms international ethical guidelines for health-related research involving humans. JAMA. 2017;317(2):135-6. https://doi.org/10.1001/ jama.2016.18977

23. Abdulghani HM, Alrowais NA, Bin-Saad NS, Al-Subaie NM, Haji AM, Alhaqwi AI. Sleep disorder among medical students: relationship to their academic performance. Med Teach. 2012;34(sup1): S37-S41. https://doi.org/10.3109/0142159X.2012.656749

24. Moayedi F, Shahabjahanlu A, Rasa F, Sadeghi P. Prevalence of sleep disorders among medical students. Res J Pharm Biol Chem Sci. 2015;6(2):894-8. https://doi.org/10.18869/ acadpub.jhs.5.1.49

25. Choueiry N, Salamoun T, Jabbour H, El Osta N, Hajj A, Rabbaa Khabbaz L. Insomnia and relationship with anxiety in university students: a cross-sectional designed study. PloS One. 2016;11(2). https://doi.org/10.1371/journal.pone.0149643

26. De la Cruz-Vargas JA, Armas-Elguera F, Cárdenas-Carranza M, Cedillo-Ramírez L. Asociación entre ansiedad y trastornos del sueño en estudiantes de medicina humana de la Universidad Ricardo Palma, julio-diciembre del 2017. Rev Fac Med Hum. 2018;18(3):2026. https://doi.org/10.25176/RFMH.v18.n3.1587

27. Hayley AC, Williams LJ, Berk M, Kennedy GA., Jacka FN, Pasco JA. The relationship between excessive daytime sleepiness and depressive and anxiety disorders in women. Aust N Z J Psychiatry. 2013;47(8):772-8. https://doi.org/10.1177/0004867413490036

28. Jaussent I, Morin CM, Ivers H, Dauvilliers Y. Incidence, worsening and risk factors of daytime sleepiness in a population-based 5-year longitudinal study. Sci Rep. 2017;7(1):111. https://doi.org/10.1038/s41598-017-01547-0 